\section{THE USE OF TOPOLOGY OF IHBI INVERTERS \\ IN PARALLEL OPERATION OF SHIP GENERATING SETS WITH PMSG GENERATORS}

DOI 10.2478/ntpe-2018-0038

\author{
prof. Sergiei German-Galkin \\ ITMO University Saint-Petersburg, Russia \\ dr inż. Dariusz Tarnapowicz \\ Maritime University of Szczecin, Poland \\ prof. Valentin S. Tomasov \\ ITMO University Saint-Petersburg, Russia
}

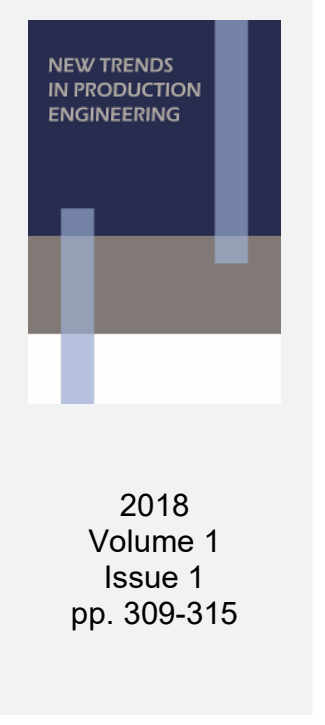

\begin{abstract}
One of the methods to improve the efficiency of the ship's propulsion is the increase of efficiency in ship generators by using permanent magnet synchronous generators (PMSG - Permanent Magnet Synchronous Generator). Due to the lack of voltage regulator in PMSG, it is necessary to use power electronic converters to maintain a constant voltage level. One of the modes of operation for a ship's power plant is a parallel work of generating sets. In the parallel work, there are problems in the fluctuation of active and reactive electrical power between generators. The article presents the concept of using inverters in the IHBI topology, which enables the parallel operation of generating sets with PMSG generators. This solution enables the adjustment of the flow of active and reactive powers between generating sets.
\end{abstract}

Keywords: PMSG, IHBI topology, generator sets

\title{
INTRODUCTION
}

The ship's power plant is one of the most important systems on the ship. The correct operation of this system determines the security of navigation - exploitation safety and safety of the crew. System failures can also create a threat to the natural environment. The ship's electrical power grid is a "soft" grid. The power of generating sets is comparable to the power of the largest electrical load on the ship. The ship's power system is vulnerable to load changes in contrast to the grid land system.

The electrical power ship's system consists of at least two generating sets (in accordance with the regulations of classification societies (Polski Rejestr Statków, 2016). Commonly in shipbuilding, there are three, four or more Diesel-Generator (D-G) autonomous sets. The D-G autonomous generating set consists of medium-speed four stroke internal combustion engine that drives self-excited synchronous generator. The parallel operation of D-G sets is conditioned by the demand for electricity and the working mode of the ship (sea voyage, maneuvers, mooring in the port).

During the sea voyage, one generating set usually works (depending on the demand for electricity), and during maneuvers (ship traveling in "difficult" water areas), the parallel operation of two generating sets is required - regardless of the electricity reception.

Figure 1 shows a typical power network on the ship.

In order to increase the economic efficiency and reduce exhaust emission by ships, shipowners are looking for solutions to optimize ship's energy system.

For the assessment of the energy system (i.e. the ship's power plant), the efficiency indicator of a power plant is used. 


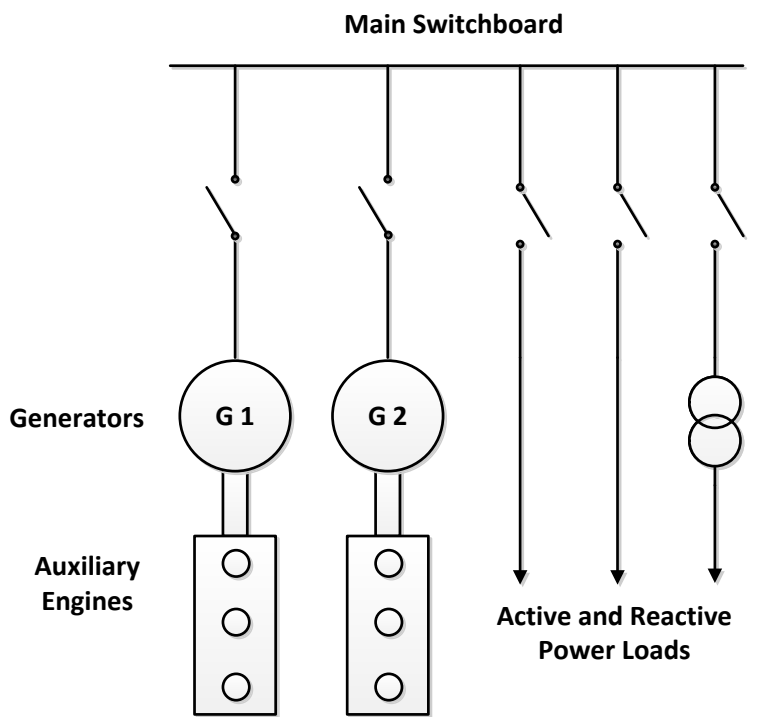

Fig. 1. Typical power network on the ship

The efficiency indicator of the power plant $\eta_{s}$ is the ratio of power on the propeller shaft to the amount of energy supplied in fuel to all ship appliances (Balcerski, 1986).

where:

$$
\eta_{\mathrm{S}}=\frac{3600 \cdot \mathrm{P}_{\mathrm{W}}}{\sum_{1}^{\mathrm{n}} \mathrm{B}_{\mathrm{i}} \cdot \mathrm{W}_{\mathrm{di}}}
$$

$P_{w}$ - power on the propeller shaft $[\mathrm{kW}]$,

$B_{i}-$ hour fuel consumption of all ship appliances $[\mathrm{kg} / \mathrm{h}]$,

$W_{d i}-$ calorific value of fuel for a given appliance $[\mathrm{kJ} / \mathrm{kg}]$

The efficiency of the power plant for a given power on the propeller shaft is determined by the total amount of fuel burned by the main engine and auxiliary engines of generating sets. By increasing the efficiency of generating sets, the efficiency of ship's power plant increases ( $\square$ s). One of the methods to increase the efficiency of generating sets is the use of Permanent Magnet Synchronous Generators (PMSG).

\section{SHIP POWER GENERATING SETS WITH PMSG GENERATORS}

In recent years, thanks to the use of technology of obtaining magnets with high energy density, the use of Permanent Magnet Synchronous Generator (PMSG) has increased. In comparison to the classic synchronous generator, PMSG has many advantages:

- High efficiency in a wide range of load

- High reliability connected with:

- Compact brushless design of electrical machine

- Lack of external excitation systems

- Lack of voltage regulator (AVR)

- Low rotor weight and inertia

- Very low vibration level

- Large number of pole pairs

Figure 2 presents a comparison of the efficiency of a classic synchronous generator (classic SG) with PMSG in a wide range of load (theswitch.com, 2018, ABB Generators Ltd., 2012).

The main advantage of PMSG in relations to classical SG is (in addition to greater efficiency) maintaining it at a high level in a wide range of load (Figure 2).

Small, lightweight, durable construction and high reliability due to the simple construction enables more efficient use of PMSG in ship power plants. 


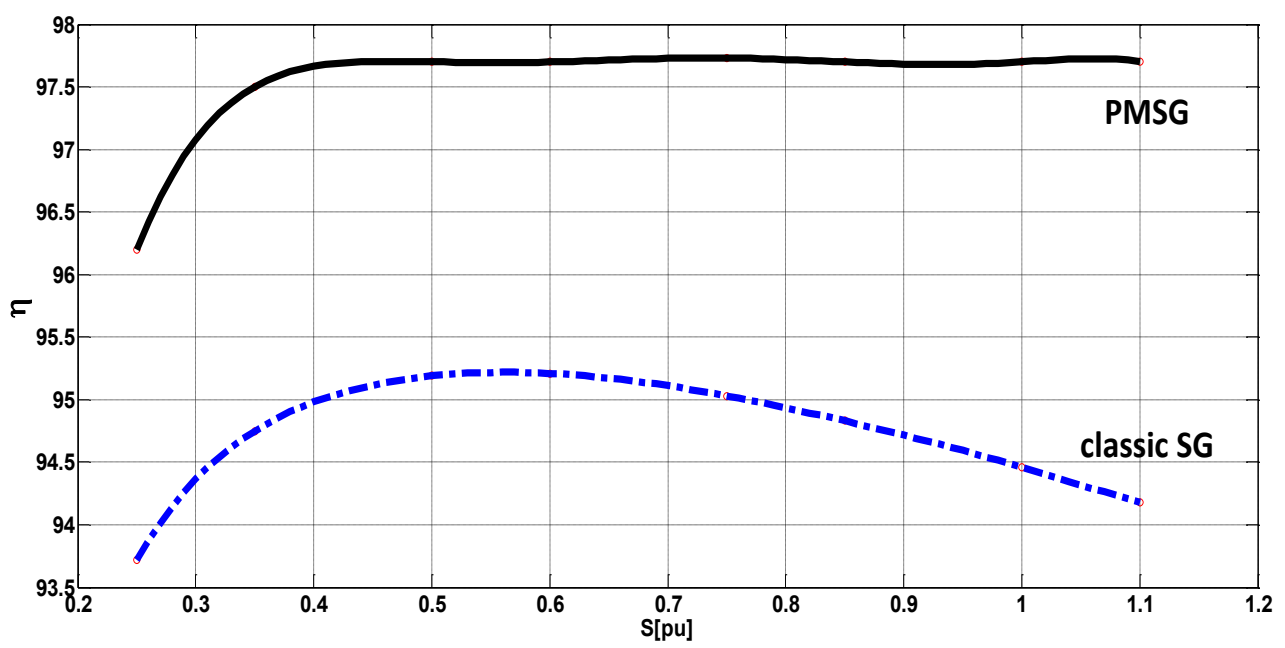

Fig. 2. Efficiency of PMSG and classical SG with a power of 650 kVA

Source: based on (theswitch.com, 2018, ABB Generators Ltd., 2012)

In order to maintain permanent network parameters in the absence of AVR, it is necessary to use (in the system with PMSG) power-electronic voltage converter. The block diagram of the autonomous generating set is presented in Figure 3.

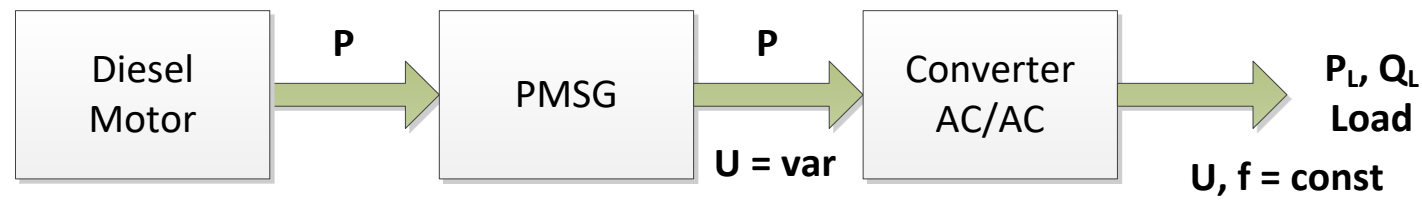

Fig. 3. Block diagram of an autonomous generating set with the use of PMSG

The specificity of a ship's power plant often requires parallel operation of generating sets. As already mentioned, the parallel work is not only required by the demand for electricity, but above all for ensuring the safety of the ship. Therefore, generating sets often work underloaded. The professional practice of the authors of this study and literature (Borkowski et all., 2013, Matuszak et all., 2015, Nicewicz et all., 2014) confirms that in the parallel operation, when travelling in "difficult water areas" and during maneuvers, the generating set is loaded with $35-45 \%$. The long-term operation of the under-loaded diesel engine of the generating set is not recommended due to incomplete combustion of fuel and in consequence - engine damage and increase of unit fuel consumption.

One of the methods to solve this problem is a parallel asymmetrical work of generating sets (equal power). The asymmetrical operation is carried out so that one unit would give $70-80 \%$ of the total power and the second one $30-20 \%$ of the total power at that time. Then after the time delay (usually a few hours), generating sets are replaced (Śmierzchalski, 2004). The set providing higher active power does not exceed the mentioned levels. Additional load changes are realized by the less-loaded set.

The asymmetrical operation of generating sets may also be required if one of the sets cannot be loaded with too much active power due to mechanical reasons.

In parallel operation of autonomous generating sets with inverters of $A C / A C$ converter should be connected in order to ensure the realization of the above-mentioned algorithm.

\section{METHODOLOGY OF RESEARCH}

Parallel operation of ship generating sets with PMSG generators

Due to the need to regulate the active and passive power distribution between two autonomous generating sets (Figure 3) working in parallel, the Isolated H-Bridge Inverter (IHBI) topology was proposed.

IHBI is a type of multi-level voltage inverter. Single bridges of single-phase inverters are connected in series to form the so-called Cascade. The main purpose of using IHBI inverters is 
to reduce the requirements for the voltage class of semiconductor devices and the improvement of the quality of waveforms generated by the inverter (Tarnapowicz, 2010, Hartman, 2007, 2008, Al-Hitmi et all. 2018). IHBI inverters are mainly use in the adjustable drives of high-power AC motors [Hartman].

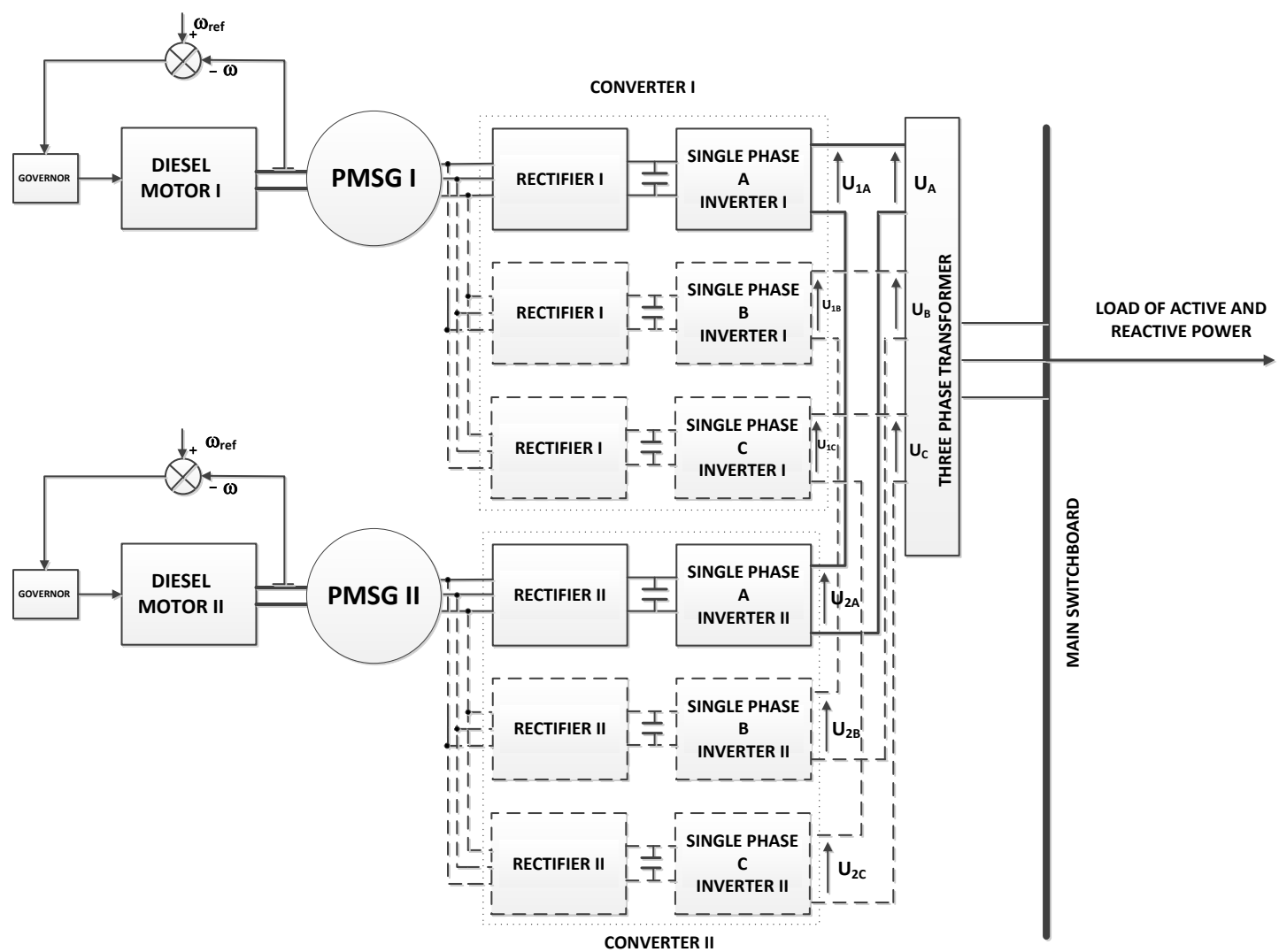

Fig. 3. Schematic diagram of the parallel operation of ship generating sets with the use of PMSG in the IHBI topology

The authors have not found in the literature the application of IHBI for power distribution of autonomous generating sets.

Figure 3 shows a schematic diagram of the connection system of ship autonomous generating sets with PMSG using the IHBI topology. By analyzing phase $A$, the UA voltage is the sum of voltages of I UA1 inverter and II UA2 inverter. UA, UB and UC voltages are the same. They are only moved 120 degree apart from each other. One phase of three-phase voltage was analyzed.

\section{Simulation researches of parallel operation for inverters in the IHBI topology}

Simulation researches of parallel operation for inverters in the IHBI topology with the possibility of active and reactive power distribution were carried out with the use of the MATLABSIMULINK simulation package. In order to simplify the tests, only the work of inverters with isolated power sources for one phase was analyzed. Figure 4 presents the simulation model of the system. 


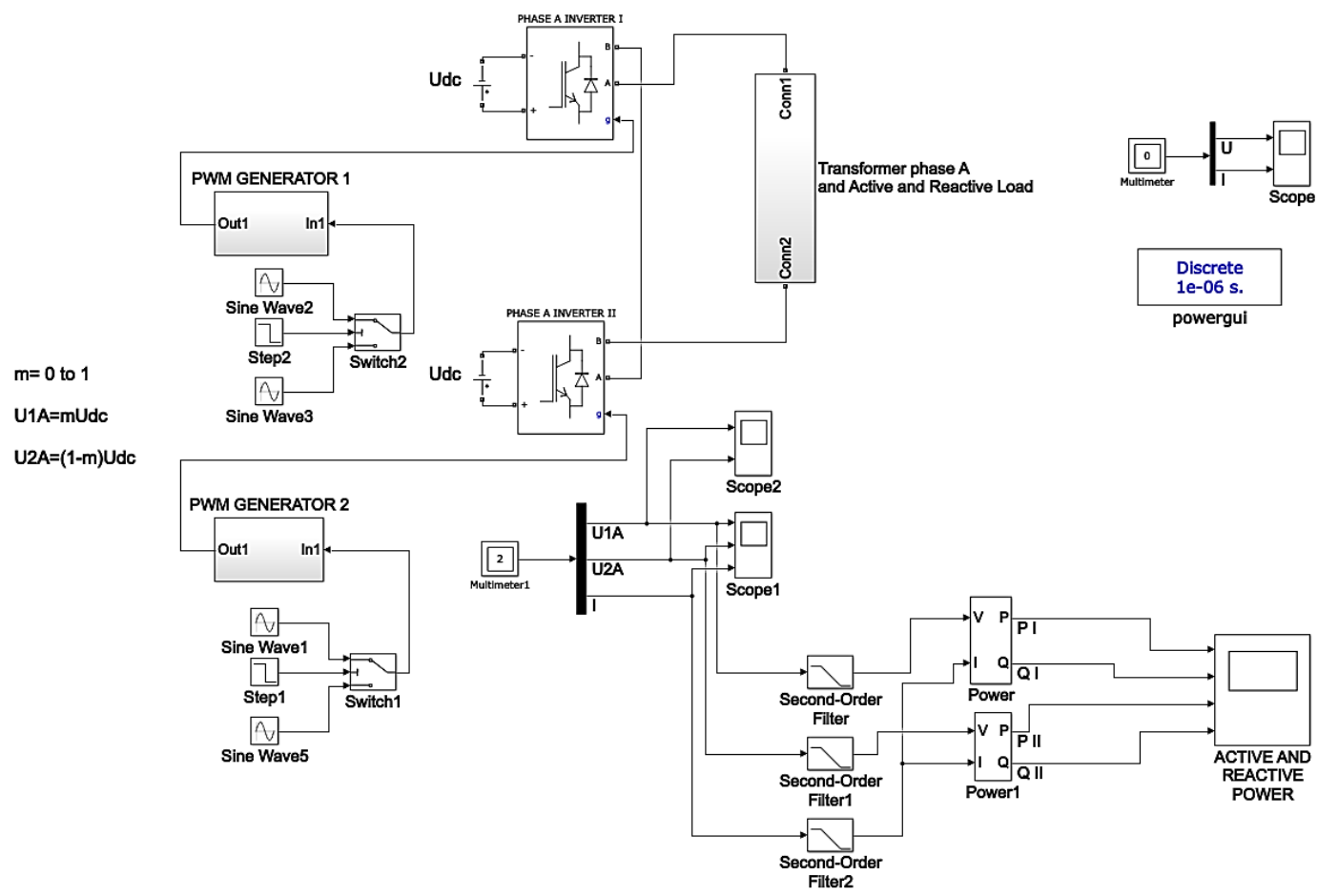

Fig. 4. Simulation model of the parallel of the parallel working system for inverters in the IHBI topology

\section{RESULTS}

The modulation method used in the analyzed topology is so-called PWM (Pulse Width Modulation). Control of the inverter I is performed with a saw-shaped modulating signal reverse than in the inverter II (INVERTER I - [lll $\left.\begin{array}{ll}0 & 0\end{array}\right]$, INVERTER II - [ $\left.\left.\begin{array}{lll}1 & 0 & 1\end{array}\right]\right)$. Figure 5 shows waveforms of output voltages $U_{1 A}$ (inverter $I$ ) and $U_{2 A}$ (inverter II) in a short time window implementing the described control strategy.

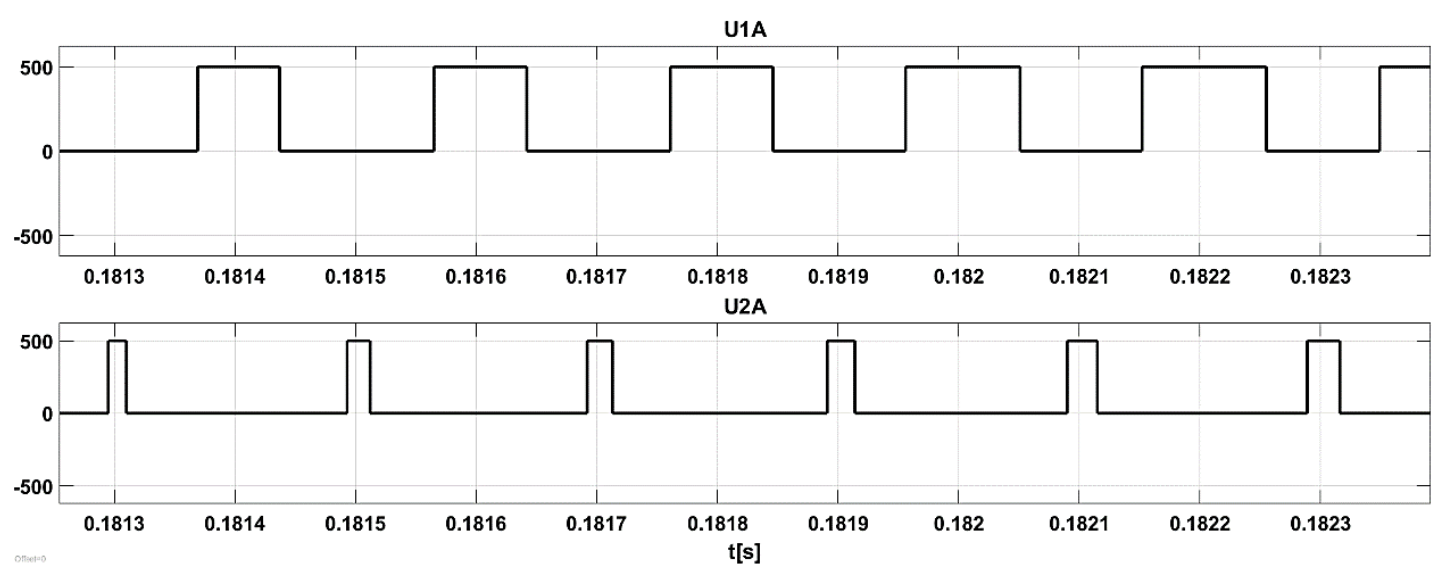

Fig. 5. Waveforms of the output voltages U1A (inverter I) and U2A (inverter II) in the IHBI topology

Figure 6 presents the waveforms of the output voltages $U_{1 A}$ (inverter I) and $U_{2 A}$ (inverter II) and the current of the receiver for phase $A I_{A}$

In accordance with the assumptions, the presented simulation researches realized a change in the distribution of active and reactive power given by generating sets. In the first time interval (from 0.02 to $0.1 \mathrm{~s}$ ), the power distribution is equal for two inverters (50\% each). At the time of $0.1 \mathrm{~s}$, there is a change in the power distribution to two inverters $-80 \%$ of inverter l's power and $20 \%$ of inverter Il's power. 

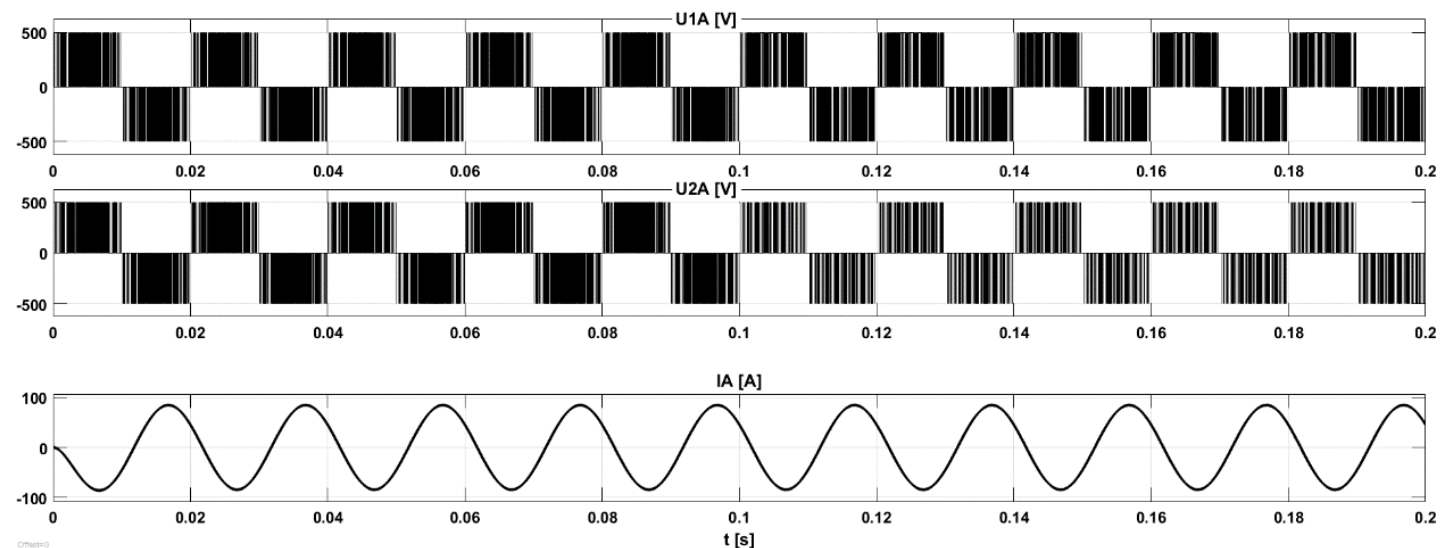

Fig. 6. The waveforms of the output voltages $U_{1 A}$ (inverter I) and $U_{2 A}$ (inverter II) and the current of the phase $A$ receiver

Figure 7 presents the result of simulation tests in the case of distribution of active power into two inverters in the IHBI system that realizes parallel operation of generating sets with the possibility of changing the power distribution.

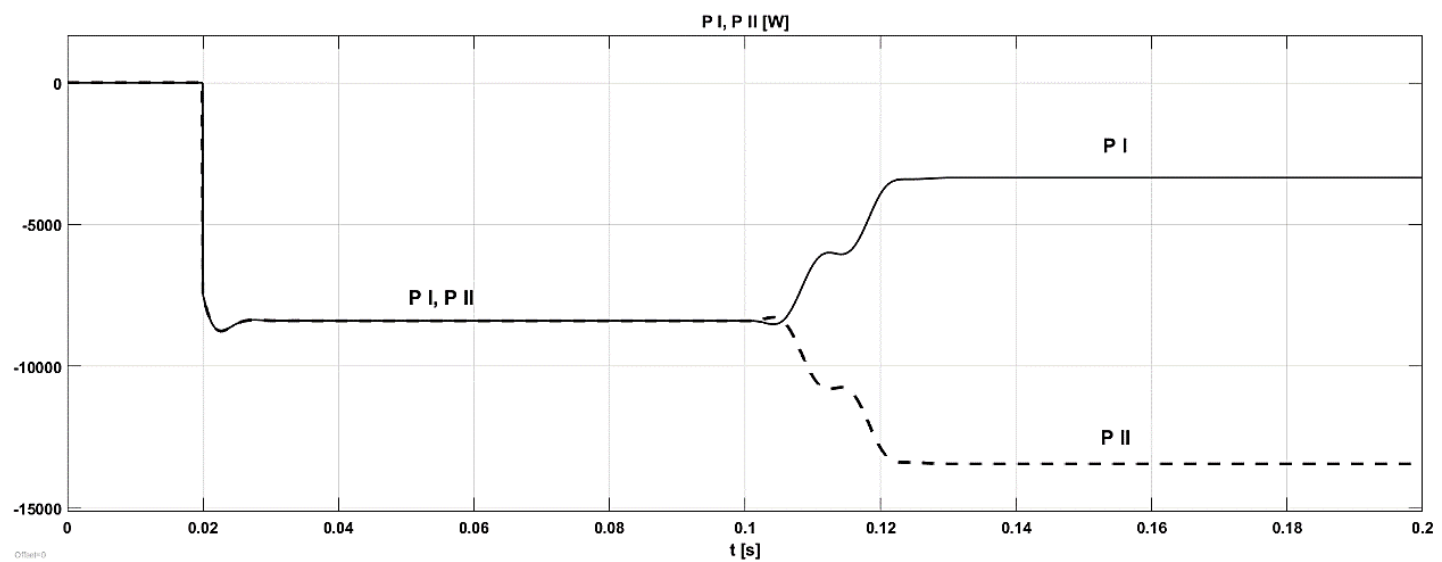

Fig. 7. Distribution of active powers into two inverters that operate in parallel in the IHBI system

Figure 8 presents the result of simulation researches in the case of distribution of reactive powers into two inverters in the IHBI system operating parallel work of generating sets.

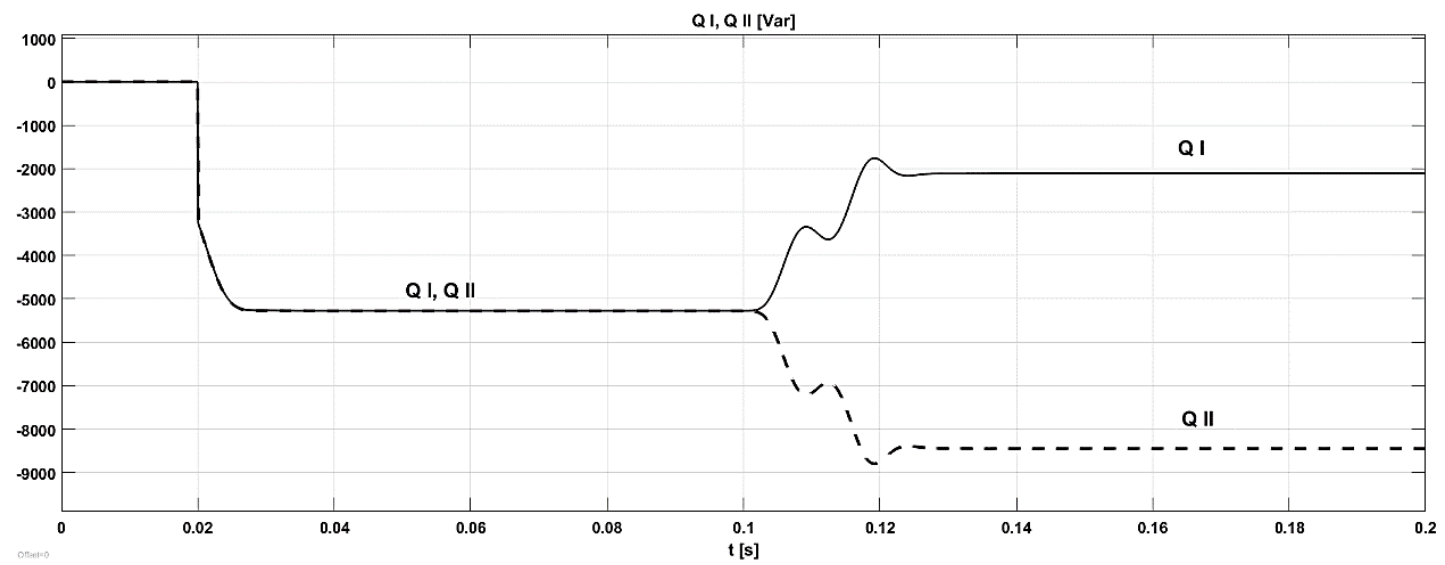

Fig. 8. Distribution of reactive powers into two parallel operating inverters in the IHBI system

\section{DISCUSSION}

In order to ensure the reliability of operation for the ship's power plant, it is necessary to ensure an uninterrupted operation of the power source at the time of failure of one of the sets. Such a solution will be provided by an electronical bypass of the inverter in the damaged set 
realized with High Power Solid-State Switches. The typical switching time of the High Power Solid-State Switches is less than $10 \mathrm{~ms}$, which does not affect the receivers.

\section{CONCLUSION}

The authors did not find any similar use of the IHBI inverters in literature. Inverters in this topology are used to withstand voltage inverter and improve the quality of generated voltage waveforms (Hartman, 2007, Rehaoulia et all., 2016)

The concept of using inverters in the IHBI topology proposed in this article enables parallel operation of autonomous generating sets with PMSG generators. The adopted control algorithm allows for adjustment of the active and reactive power distribution between generating sets. The results obtained in simulation researches confirmed the theoretical assumptions.

\section{ACKNOWLEDGEMENTS}

This research outcome has been achieved under the research project: Nowoczesne technologie w systemach "Shore to Ship" No 2/S/IEiAO/16 financed from a subsidy of the Ministry of Science and Higher Education for statutory activities

\section{REFERENCES}

ABB Generators Ltd., (2012). Technical Specification: 8AMG 5862150. Available at: https://library.e.abb.com/public/26c157c8fee68fd848257a1c00116ca6/5862150-BAMG\%200355BB04\%20Technical\%20specification.pdf. [Accessed 20 Jan. 2018]

Al-Hitmi, M., Ahmad, S., Iqbal, A., Padmanaban, S. and Ashraf, I. (2018). Selective Harmonic Elimination in a Wide Modulation Range Using Modified Newton-Raphson and Pattern Generation Methods for a Multilevel Inverter. ENERGIES MDPI,11(2)

Balcerski, A. (1986). Siłownie okrętowe. Politechnika Gdańska, Gdańsk.

Borkowski, T., Nicewicz, G. and Tarnapowicz, D. (2013). The methodology used in defining air pollution from ships mooring in ports. Scientific Journals of the Maritime University of Szczecin Volume: 36 Issue: 2 Pages: 17-22 Published: 2013

Hartman, M. (2007). Wielopoziomowe falowniki napięcia. Fundacja Rozwoju Akademii Morskiej w Gdyni, Gdynia

Hartman, M. (2008). Selected elements of comparison analyse of multilevel voltage inverters. Przeglad Elektrotechniczny, 84(4), pp.1-3

Matuszak, Z., Nicewicz, G., Stoklosa, J., Kaplon, A. and Jurecki, R. (2015) Results of load's observation for selected marine electric power plants systems in floating objects. Selected Problems of Electrical Engineering and Electronics WZEE. KIELCE, POLAND, SEP 1719, 2015

Nicewicz, G.,Sosinski, M. and Tarnapowicz, D. (2014) Identification of power factor in marine electrical grid. Geoconference on Energy and Clean Technologies, VOL II, 14th International Multidisciplinary Scientific Geoconference (SGEM) pp 391-398, Albena, BULGARIA, JUN 17-26, 2014

Polski Rejestr Statków, (2016). Przepisy klasyfikacji i budowy statków morskich część VIII. Copyright by Polski Rejestr Statków S.A., Gdańsk 2018

Rehaoulia, A., Rehaoulia, H., Fnaiech, F. (2016). Multilevel Inverters Power Topologies and Voltage Quality: A Literature Review. Journal of Magnetics 21(1), pp. 83-93

Śmierzchalski, R. (2004). Automatyzacja systemu elektroenergetycznego statku. Gdańsk.

Tarnapowicz, D.(2010). The conception of the use of multi-level inverters in the shipping shaft generator systems of high power. Scientific journals of the maritime university of Szczecin. 22, pp. 67-70

theswitch.com, (2018). Official Website of Yaskawa Electric Corporation. [online] Available at: //theswitch.com/download-center/data-sheets/marine/ [Accessed 20 Jan. 2018 